University of Wollongong

Research Online

Faculty of Social Sciences - Papers (Archive) Faculty of Arts, Social Sciences \& Humanities

$1-1-2018$

\title{
Teacher Disposition Scale (TDS): construction and psychometric validation
}

Conor West

University of Wollongong, cw606@uowmail.edu.au

Amanda Ann Baker

University of Wollongong, abaker@uow.edu.au

John F. Ehrich

Monash University, jehrich@uow.edu.au

Stuart Woodcock

Macquarie University, stuart.woodcock@mq.edu.au

Sahar Bokosmaty

University of Wollongong, saharb@uow.edu.au

See next page for additional authors

Follow this and additional works at: https://ro.uow.edu.au/sspapers

Part of the Education Commons, and the Social and Behavioral Sciences Commons

Research Online is the open access institutional repository for the University of Wollongong. For further information contact the UOW Library: research-pubs@uow.edu.au 


\title{
Teacher Disposition Scale (TDS): construction and psychometric validation
}

\begin{abstract}
Despite the growing prominence and importance of the field of teacher dispositions for addressing selection criteria and assessment in educational research, there is an absence of psychometrically evaluated instruments to facilitate investigations. Furthermore, research thus far has not explored the relationship between teacher dispositions and better student outcomes. To address this paucity, key dispositional factors conducive to successful teaching and learning were identified through interviewing high performing teachers. Based on the interview, data a 24-item Teacher Disposition Scale (TDS) was constructed consisting of five dimensions: Motivation to teach; Teacher efficacy; Willingness to learn; Conscientiousness; and Interpersonal and communication skill. The scale was psychometrically tested on 179 pre-service undergraduate students at an Australian university. Both factor analysis and Rasch measurement modelling indicated evidence of a reliable and valid multi-dimensional scale. The article concludes with a discussion on the implications of the scale for future research.
\end{abstract}

\section{Keywords}

psychometric, teacher, construction, disposition, (tds):, scale, validation

\section{Disciplines}

Education | Social and Behavioral Sciences

\section{Publication Details}

West, C., Baker, A., Ehrich, J. Fitzgerald., Woodcock, S., Bokosmaty, S., Howard, S. J. \& Eady, M. J. (2018). Teacher Disposition Scale (TDS): construction and psychometric validation. Journal of Further and Higher Education, Online First 1-16.

\section{Authors}

Conor West, Amanda Ann Baker, John F. Ehrich, Stuart Woodcock, Sahar Bokosmaty, Steven J. Howard, and Michelle J. Eady 


\title{
Teacher Disposition Scale (TDS): construction and psychometric validation
}

\author{
Conor West - University of Wollongong \\ Amanda Baker - University of Wollongong \\ John Fitzgerald Ehrich - Macquarie University \\ Stuart Woodcock - Macquarie University \\ Sahar Bokosmaty - University of Wollongong \\ Steven J. Howard - University of Wollongong \\ Michelle J. Eady - University of Wollongong
}

\section{Introduction}

Changing negative trends in the shape and function of the teaching workforce are now prompting global investigations. Data from the United Kingdom, the United States, Canada and Australia suggest anywhere from $24 \%$ to $40 \%$ of graduating teachers leave the profession within three to five years (Kyriacou and Kunc, 2007; McConney, Price, and Woods-McConney, 2012; Paris, 2010; White, Gorard, and See, 2006). Such high attrition rates produce obvious financial costs, but can also have a negative impact on early career teachers' confidence, as well as the reputation and credibility of universities and the profession. Most attrition in teaching is linked to job burnout, as a response to prolonged workplace stress (Fernet, Guay, Senécal, and Austin, 2012). This may, however, be redressed through more focused selection criteria and assessment in initial teacher education (ITE), with the purpose of identifying whether pre-service teachers possess dispositions deemed necessary for successful teachers. These dispositions may be understood in terms of promoting both resiliency and effective teaching (i.e., traits that are formally or informally recognised as beneficial to teaching successfully) (Cornelius-White, 2007; Darling-Hammond, 2006). Given this background, the current study aimed to develop and evaluate a Teacher Disposition Scale (TDS) that can be used to explore key dispositions considered conducive to successful teaching and 
learning in Australia among primary school teachers and trainee school teachers.

\section{Increasing Focus on Teacher Dispositions}

Increased reference to 'disposition' in the educational research literature reflects current attempts to outline the vague behavioural tendencies that are often identified in effective teacher practice research (NCATE, 2013; NSW DEC, 2013). Defining what is meant by dispositions, however, is problematic (e.g., Borko, Liston, and Whitcomb, 2007; Damon, 2007; Welch, Pitts, Tenini, Kuenlen, and Wood, 2010). The National Council for Accreditation of Teacher Education (NCATE) (2008), for example, defines dispositions as:

\footnotetext{
'Professional attitudes, values, and beliefs demonstrated through both verbal and non- verbal behaviors as educators interact with students, families, colleagues, and communities. These positive behaviors support student learning and development' (89-90) and include dispositions such as 'fairness and the belief that all students can learn' (90).
}

NCATE's definition is strongly connected to 'observable behaviours' (90). However, Schussler (2006) argues that dispositions are a 'point of convergence' between behaviour and thought, where actions are also influenced by prior life experience, beliefs, and assumptions. She proposes that dispositions form the very heart of 'teachers' decisions to think and act' (252). Taken altogether, it can be argued that dispositions are a set of latent psychological traits (i.e. they impact behaviour but are unobservable) that predispose someone to behave in particular ways. They are contextual but relatively stable within those contexts. Theories and existing instruments divide at this point on how these latent traits are best understood and studied, whether as observable behaviours, belief statements or personality traits (O’Neill, Hansen, and Lewis, 2014). The current study adopts this position of dispositions as observable 
primarily through manifest behavioural tendencies, influenced by underpinning values, attitudes, beliefs and personality traits that create a disposition to act in specific ways (Chamorro-Premuzic, 2011). Furthermore, as intention to act is viewed as a major precedent to observable behaviour (Fishbein \& Ajzen, 2010), self-reported data can provide invaluable insights into the dispositions of pre-service and in-service teachers. Once this foundational work has been established, future research may incorporate future research may incorporate objective observations of desirable teacher dispositions to temper any bias from self-reporting and establish a disposition-behaviour association.

There is growing recognition that teacher education programmes focusing solely on content knowledge and teaching skills are insufficient if divorced from an examination of teachers' dispositions, or inclinations, towards applying what they have learned to their current or future teaching practice (Borko, Liston, and Whitcomb, 2007). Conversely, teacher education programmes that address and support the development of positive and professionally conducive dispositions - especially in assisting candidates 'in fostering awareness' by 'uncover[ing] knowledge of themselves' (Schussler, Bercaw, and Stooksberry, 2008, 351) - have the potential to positively shape pre-service teachers' perceptions and expectations. In the United States, addressing dispositions in teacher training programmes has been a requirement of the accreditation process at state and national levels since 2002 (NCATE, 2008). Similarly, Australian education recognizes that, in addition to professional knowledge and skills, teacher dispositions are an equally important contributor to effective teaching, particularly in relation to characteristics such as empathy, enthusiasm and fairness (CESE, 2013; Cornelius-White, 2007; Darling-Hammond, 2006; OECD, 2005). In England, positive non-academic qualities, such as high student expectations, efficacy and leadership abilities, have been identified among Teach First candidates (Rice, Volkoff 
and Dulfer, 2015; O’Neill, Hansen, and Lewis, 2014). However, empirical evidence of the importance of particular dispositions (or dispositions at all) in teaching is limited, due in large part to the complexity of teacher dispositions and lack of suitable or reliable measurement instruments. A highly robust and reliable disposition scale is needed as a first step in addressing this complex issue.

\section{The Current Study}

Despite the importance and growing prominence of teacher disposition research (NSW DEC, 2013; TEMAG, 2014), existing research rarely agrees on dispositions considered essential to effective teaching. For instance, little research establishes what composition(s) of dispositions are related to better student outcomes. Nominated factors range from motivation to verbal ability to fairness (Barber and Mourshed, 2007; CESE, 2013; Stronge, Ward, and Grant, 2011). However, the extent to which these dispositions overlap, the dispositions that are especially important, and the behaviours they individually or conjointly influence remain unclear. This is exacerbated by a lack of suitable disposition instruments, which limits empirical investigation of these questions (O’Neill, Hansen, and Lewis, 2014). The tools that do exist often lack psychometric evaluation or consultation with current and highly accomplished members of the teaching profession. However, this has not stopped the development and use of many institutional dispositional scales, many sharing common dispositional themes that are proposed as demonstrating effective teaching such as ethics, professional growth and service (Young and Wilkins, 2008).

The current study thus aimed to develop a Teacher Disposition Scale (TDS) to identify key dispositions for successful teaching and learning through a mixed methods design. In contrast to many existing tools, the current scale was derived in consultation 
with highly accomplished teachers, and the results of the pilot study of this initial scale were used to: (1) derive a core set of teacher dispositions from those identified in the literature and by the highly accomplished teachers; (2) identify specific behavioural tendencies that are associated with each of these dispositions; and (3) evaluate the psychometric properties of the resulting scale. While it is unrealistic to expect one instrument to adequately predict quality amongst teachers, the current study can contribute to the essential discussion, evaluation, research, and professional support needed for fostering positive teacher dispositions amongst pre-service and early career teachers.

\section{Materials and Methods}

Prior to the commencement of the study, permission to conduct the research was first obtained through the university's Human Ethics Review Committee. As such, all participants provided written informed consent prior to participating in the study. The participants, interview procedures and TDS development and piloting are discussed in detail below.

\section{Participants}

Qualitative interviews were conducted with 12 current, experienced primary school teachers who were recognised as 'Highly Accomplished Teachers' (HATs) by their federal and state governments. A joint initiative by the federal and New South Wales (NSW) State Governments' joint initiative established guidelines for recognising a HAT within NSW Government Schools as 'an excellent teacher who models high quality teaching for his/her colleagues across the school and will lead other teachers in the development and refinement of their teaching practice to improve student learning outcomes' (NSW DET, 2009, 3). Of the 146 recognised HATs during the period 2009- 
2013 (after which the programme ceased), invitations to participate were extended to all 92 who taught in primary schools. This resulted in 12 HAT (11 female; 1 male) volunteers, ranging from 32-59 years of age and from 10-30 years of teaching experience. They taught in a cross-range of settings, including urban (6), semi-urban (4) and rural (2).

The purpose of the interviews was to identify the behaviours and dispositions of highly effective teachers, which could be reconciled with and supplemented by those noted in the literature, to develop and evaluate a TDS. For a full description of the HAT interview procedures and protocol, see Online Supplements 1 and 2. The resulting scale was subsequently piloted with 179 fourth-year undergraduate Bachelor of Education (Primary) students enrolled at a large metropolitan Australian university. At this point, these students had completed at least 16 weeks of professional experience in schools across their four years of study. The sample was $82 \%$ female, which is consistent with the gender composition of primary school teachers in the state (NSW DEC, 2015). The mean age of participants was 23 years and 8 months, ranging from 21-44 years of age. The distribution of ages was positively skewed, as expected, such that there was a greater concentration of young students ( $89.9 \%$ were $<30$ years of age).

\section{Qualitative Data Collection and Analysis}

Prior to interviews with the HATs, and as stimulus for identification and discussion of the dispositions and behaviours of highly effective teachers, an initial list of dispositions was compiled based on an extensive review of teacher disposition and effective teacher literatures (theoretical and empirical). Discussion of and agreement on a comprehensive set of dispositions involved a series of four meetings among the researchers to categorise, collapse, and further expand the identified dispositions. The end result was a list of dispositions that the literature highlighted as characteristic of good/effective 
teachers. The list was collapsed into four core dispositions, containing a range of relevant teacher behaviours: professional knowledge (27 behaviours); interpersonal skills, community and communication (9 behaviours); ethics and professionalism (5 behaviours); and attitude and personal attributes (12 behaviours). This interview protocol (See Online Supplement 1) was used with the HAT participants to identify, discuss, and prioritise the characteristics, behaviours, and beliefs of highly effective teachers.

Participants chose face to face $(n=2)$, telephone $(n=4)$, Skype $(n=2)$ or video conferencing $(n=3)$ interviews conducted from the university office of one of the researchers. The audio-recorded interviews lasted between 65 - 100 minutes. The HATs were all emailed the interview protocol in advance of the meeting to allow time to review both the interview questions and the extensive list of dispositions that had been derived from the literature. Subsequently, as part of the interview, they were asked to circle the dispositions that they considered essential for an effective teacher, rank them in order of importance, and add any dispositions that they deemed important but were not included in the list.

Several open-ended questions were included in the interview to provide HATs with an opportunity to discuss in greater detail dispositions they considered important for effective teachers. Examples of these questions included, 'What do you feel are the most important dispositions in an effective teacher?' and 'In your experience, what dispositions do you feel newly graduating teachers bring as strengths?' This permitted clearer descriptions of the dispositions and behaviours that should feature in the resultant TDS. 
Following the interviews, all audio recordings were transcribed and the researchers formed preliminary categories from these data. The transcribed data was first entered into NVivo 10 and then coded based on the initial start list of codes provided to teachers in the original interview protocol. Two of the researchers separately coded the same four transcribed interviews. The coding of the initial four transcripts was compared, resulting in roughly $70 \%$ agreement. Discrepancies in coding were discussed and consensus reached, before the remaining seven transcribed interviews were coded. Development of the final version of these categories (i.e., dispositions), which formed a foundation of the TDS, is discussed later in the Results section.

\section{Quantitative Data Collection and Analysis}

On the basis of the qualitative analysis of the HAT interview data, a preliminary version of the TDS was created. This initial TDS consisted of 31 self-reported items indicating the extent to which the respondents engaged in the identified behaviours (each believed to be underpinned by a core set of teacher dispositions). This was indicated on a sevenpoint Likert scale, ranging from $0=$ never to $6=$ all the time. A seven-point scale was adopted given the desire for interpretable scale point meanings (e.g., $4=$ half the time, 5 $=\mathrm{a}$ bit more than half the time, $6=$ much more than half the time but not all the time, 7 $=$ all the time) and the desire for sensitivity to change (i.e., a shift from $3=$ sometimes to $4=$ usually is, in real-world terms, a dramatic shift). This use of a seven-point scale is also supported by evidence of the comparable reliability of such scales (Krosnick and Presser, 2010). On the basis of the analysis of the HAT interview data, and consistent with those core non-cognitive abilities of successful teachers identified by the Australian Institute for Teaching and School Leadership (AITSL, 2015), items were 
expected to cluster into five factors: Teacher Efficacy; Interpersonal \& Communication Skills; Motivation to Teach; Willingness to Learn; and Conscientiousness. Names of these five factors were derived directly from government policy to create an instrument aligned with the current policy and legislative environment (ibid).

The TDS was then piloted with the 179 undergraduate students and their responses were analysed quantitatively. Pilot TDS data were initially subjected to exploratory factor analysis to evaluate our a priori set of dispositions against the empirically derived factor structure of the TDS's initial 31 effective teaching behaviours or traits. Where the factor analysis was unclear (e.g., cross-loadings of items), a theoretically and empirically guided decision was taken based on our a priori categorisations to identify the subscale for the item. Reliability analysis (Cronbach's alpha) was then conducted on each of the TDS's identified subscales to evaluate the reliability with which they evaluated their underlying construct (i.e., disposition). Finally, Rasch analysis was conducted to apply a modern test theory approach to evaluating the validity and reliability of the TDS. The Rasch model is a probabilistic model that algebraically converts Likert scale (raw score) data into linear measures. The model is based on the probability of achieving a hierarchical and ideal response pattern (i.e., a Guttman scalar pattern; Tennant and Conaghan, 2007). If the data fitted to the Rasch model meet the strict measurement principles of the model then the scale can be assumed to function properly - that is, to consist of interval data (i.e., linear measures). A linear scale with equal intervals or units is a fundamental criterion for accurate measurement (see Wright, 1997). Misfit of the data to the model indicates that the scale is not linear. 


\section{Results}

\section{Qualitative Results}

The qualitative analysis of the HAT interview transcripts and the annotations on the returned interview protocol sheets highlighted that several of the original codes (dispositions) derived from the literature needed to be transformed or merged to more accurately reflect the HATs' views of important dispositions (Creswell and Creswell, 2018). For instance, 'Reflective' was subsumed under the disposition labelled 'Engages in evaluative practice of pedagogy', based on the teachers' description of their reflective practices being connected to how they teach. For example, HAT 1 explained that:

I keep thinking maybe the most important thing is being reflective; maybe that's reflecting on what you do and reflecting on... not just on what you taught well or what you didn't teach well but, you know, the way that you communicated with someone or the way that you engaged with the kids out in the play[ground].

In addition, a new disposition of 'Possesses professional knowledge' was added to the original list due to 8 of the 12 teachers highlighting this as a key disposition. For instance, HAT 5 noted that 'the most important disposition is a good knowledge of pedagogy' and HAT 8 argued that 'our professional knowledge is required for all of those other categories [dispositions] to really fall in place'. The following is a list of the dispositions considered essential by at least two-thirds of the HATs:

(1) Shows a passion for teaching (12 participants)

(2) Engages in evaluative practice of pedagogy (11 participants)

(3) Displays a genuine concern for students' well-being (10 participants)

(4) Shows a passion for students' learning (9 participants) 
(5) Copes well with change and ambiguity (9 participants)

(6) Foresees the need to differentiate for diverse students (9 participants)

(7) Possesses professional knowledge (8 participants)

(8) Demonstrates a level of overall teacher professionalism (8 participants)

Following this analysis, the research team met twice to discuss these results and to further refine the disposition list to: better reflect the findings from the HAT data, ensure similar dispositions were grouped together and ensure that the wording would still be clear in meaning for less-experienced teachers. This final list, presented in the form of questionnaire items, was then returned to the HATs for further feedback. After only minor revisions based on the HATs' feedback, the following five core dispositions and associated behaviours were finalised for the pilot questionnaire: Attitudes and Attributes (10 traits), Interpersonal (6 traits), Professionalism (5 traits), Commitment to Learning (4 traits) and Purpose and Vision for Students' Learning (6 traits). These were then adjusted to consider current dispositional policy (AITSL, 2015) and tested through quantitative analysis, forming the final five dispositions and associated behaviours included in the final TDS scale: Motivation to Teach (5 traits), Teacher Efficacy (7 traits), Willingness to Learn (4 traits), Conscientiousness (3 traits) and Interpersonal and Communication Skills (7 traits).

\section{Quantitative Results}

Given sample size constraints that precluded robust confirmatory factor analysis, an exploratory factor analysis (EFA), reliability analysis (i.e., Cronbach's alpha), and Rasch analysis were performed to evaluate the scale. 


\section{Exploratory Factor Analysis (EFA)}

To evaluate the factor structure of the scale, exploratory factor analysis (EFA) using maximum likelihood estimation and an oblique (direct oblimin) factor rotation was conducted. This data-driven analysis sought to separate sets of items (subscales) based on the extent to which they appeared to be underpinned by (associated with) a common underlying characteristic (e.g., disposition). Kaiser-Meyer-Olkin statistics (KMO = 0.899 ) and Bartlett's test of sphericity, $X^{2}(325)=2502.74, p<.001$, indicated sufficient sample size and inter-item correlations for this analysis. Results identified five factors/subscales (accounting for $61.37 \%$ of the variance); this was also supported by a scree plot. The factors/subscales (see Table 1) were interpreted as: (1) a five-item Motivation to Teach subscale; (2) a seven-item Teacher Efficacy subscale; (3) a fouritem Willingness to Learn subscale; (4) a three-item Conscientiousness subscale; and (5) a seven-item Interpersonal \& Communication Skills subscale. All items loaded well (standardised factor loadings $>0.30$ ) on these five factors.

Table 1. Factor loadings by Teacher Disposition Scale (TDS) item.

\section{Factor}

1. Considers and employs a variety of effective teaching strategies

2. Approaches the teaching profession with adequate preparation

3. Demonstrates strong overall teacher professionalism at all times inside the school context

4. Demonstrates on-going effective collaboration with whole school community

5. Engages in effective problem solving strategies

6. Engages all students to participate inclusively in communications and collaborations

7. Possesses strong verbal communication skills (speaking and listening)

\begin{tabular}{|l|c|c|c|c|}
\hline 1 & 2 & 3 & 4 & 5 \\
& .70 & & & \\
& .70 & & & \\
& .54 & & & \\
& .46 & & & .60 \\
\hline
\end{tabular}




\begin{tabular}{|c|c|c|c|c|c|}
\hline $\begin{array}{l}\text { 8. Displays genuine empathy, warmth and compassion } \\
\text { for students }\end{array}$ & .35 & .36 & & & \\
\hline $\begin{array}{l}\text { 9. Engages in effective classroom management } \\
\text { strategies }\end{array}$ & & .60 & & & .22 \\
\hline 10. Engages in reflective practices of pedagogy & & .26 & & & .35 \\
\hline $\begin{array}{l}\text { 11. Shows a willingness to facilitate extra-curricular } \\
\text { activities }\end{array}$ & & & & & .45 \\
\hline 12. Appreciates students' individual differences & .25 & .37 & .23 & .25 & \\
\hline 13. Possesses strong written communication skills & & & & & .59 \\
\hline 14. Possesses strong non-verbal communication skills & & & & & .63 \\
\hline 15. Treats everyone fairly and equitably & .31 & .23 & & & \\
\hline 16. Fosters students' self-directed learning & & & .45 & & .26 \\
\hline 17. Seeks support and advice from others & & & .94 & & \\
\hline $\begin{array}{l}\text { 18. Incorporates professional learning and feedback into } \\
\text { practice }\end{array}$ & .23 & & .67 & & \\
\hline 19. Has high expectations of students & .25 & & .42 & & \\
\hline 20. Shows a passion for teaching & .44 & & & & \\
\hline $\begin{array}{l}\text { 21. Demonstrates a passion and responsibility for } \\
\text { students' learning }\end{array}$ & .65 & & & & \\
\hline $\begin{array}{l}\text { 22. Understands their role and responsibilities in the } \\
\text { school context }\end{array}$ & .69 & & & -.27 & \\
\hline 23. Demonstrates a commitment to students' learning & .33 & & .20 & -.24 & \\
\hline 24. Shows a commitment to teaching & .26 & & & -.64 & \\
\hline $\begin{array}{l}\text { 25. Demonstrates strong overall teacher professionalism } \\
\text { at all times outside the school context }\end{array}$ & & & & -.47 & \\
\hline 26. Foresees the need to differentiate for diverse students & & .20 & & -.39 & \\
\hline
\end{tabular}

Note. Factor loadings $<.20$ have been supressed. Bolding of factor loadings indicates factor that each item was aligned to. In all cases, this was the factor on which it showed the highest loading (all > .30). 
Reliability analyses were then conducted to evaluate the consistency with which the subscale items were underpinned by a common underlying characteristic.

Cronbach's alpha suggested acceptable to very good reliability for all subscales (ranging from 0.70-0.87; Table 2). Subscale correlations ranged between $r=0.45$ (conscientiousness with interpersonal and communication skills) and 0.70 (teacher efficacy with interpersonal and communication skills), indicating that subscales were unique in what they captured while still sharing a common core.

Table 2. Descriptive statistics by subscale.

$M \quad S D$

\begin{tabular}{|c|c|c|c|}
\hline \multicolumn{2}{|c|}{ Subscale 1: Motivation to Teach (Cronbach's $\alpha=.87$ ) } & \multirow{2}{*}{$\begin{array}{r}5.34 \\
5.44\end{array}$} & \multirow{2}{*}{$\begin{array}{l}\mathbf{0 . 5 7} \\
0.67\end{array}$} \\
\hline 15 & Treats everyone fairly and equitably & & \\
\hline 20 & Shows a passion for teaching & 5.31 & 0.74 \\
\hline 21 & Demonstrates a passion and responsibility for students' learning & 5.48 & 0.64 \\
\hline 22 & Understands their role and responsibilities in the school context & 5.39 & 0.66 \\
\hline 23 & Demonstrates a commitment to students' learning & 5.10 & 0.80 \\
\hline \multicolumn{2}{|c|}{ Subscale 2: Teacher Efficacy (Cronbach's $\alpha=.86$ ) } & 5.12 & 0.61 \\
\hline 1 & Considers and employs a variety of effective teaching strategies & 4.83 & 0.79 \\
\hline 2 & Approaches the teaching profession with adequate preparation & 4.98 & 0.97 \\
\hline 3 & $\begin{array}{l}\text { Demonstrates strong overall teacher professionalism at all times inside } \\
\text { the school context }\end{array}$ & 5.36 & 0.80 \\
\hline 6 & $\begin{array}{l}\text { Engages all students to participate inclusively in communications and } \\
\text { collaborations }\end{array}$ & 4.97 & 0.91 \\
\hline 8 & Displays genuine empathy, warmth and compassion for students & 5.57 & 0.64 \\
\hline 9 & Engages in effective classroom management strategies & 4.80 & 0.96 \\
\hline 12 & Appreciates students' individual differences & 5.37 & 0.72 \\
\hline \multicolumn{2}{|c|}{ Subscale 3: Willingness to Learn (Cronbach's $\alpha=.79$ ) } & 5.05 & 0.63 \\
\hline 16 & Fosters students' self-directed learning & 4.71 & 0.85 \\
\hline 17 & Seeks support and advice from others & 5.11 & 0.87 \\
\hline 18 & Incorporates professional learning and feedback into practice & 5.07 & 0.79 \\
\hline 19 & Has high expectations of students & 5.30 & 0.70 \\
\hline \multicolumn{2}{|c|}{ Subscale 4: Conscientiousness (Cronbach's $\alpha=.70$ ) } & 5.06 & 0.79 \\
\hline 24 & Shows a commitment to teaching & 5.37 & 0.78 \\
\hline 25 & $\begin{array}{l}\text { Demonstrates strong overall teacher professionalism at all times } \\
\text { outside the school context }\end{array}$ & 4.95 & 0.98 \\
\hline
\end{tabular}




\begin{tabular}{|clcc|}
26 & Foresees the need to differentiate for diverse students & 4.87 & 1.21 \\
\hline Subscale 5: Interpersonal \& Communication Skills (Cronbach's $\boldsymbol{\alpha =} \mathbf{8 2}$ ) & $\mathbf{4 . 7 9}$ & $\mathbf{0 . 6 3}$ \\
\hline 4 & $\begin{array}{l}\text { Demonstrates on-going effective collaboration with whole school } \\
\text { community }\end{array}$ & 4.52 & 1.08 \\
7 & Engages in effective problem solving strategies & 4.72 & 0.78 \\
10 & Possesses strong verbal communication skills (speaking and listening) & 5.08 & 0.89 \\
11 & Shows a willingness to facilitate extra-curricular activities & 4.73 & 0.92 \\
13 & Possesses strong written communication skills & 4.83 & 1.06 \\
14 & Possesses strong non-verbal communication skills & 4.93 & 0.77 \\
\hline
\end{tabular}

\section{Rasch Analysis}

Rasch analyses were then conducted to evaluate the scale on the basis of consistency of the actual data with participants' latent dispositions and their expected responses to scale items. These analyses used the polytomous Rasch model with partial credit parameterisation (Masters, 1982) using Rasch Unidimensional Measurement Modeling (RUMM) 2030 software (Andrich, Sheridan, and Luo, 2010). Rasch analyses were run on each of the five subscales as identified by the EFA (Table 3). All scales were tested for (1) the fit of the data to the Rasch model, indicating that the observed (raw data) fit the theoretical expectations of the model; (2) the functioning of individual items within each scale, which indicates how well individual items function relative to other items (misfit can indicate the measurement of other unintended constructs); and (3) the unidimensionality of each scale, to ensure that only one latent disposition is measured per scale.

Table 3. Fit of the 5 scales to the Rasch model.

\begin{tabular}{|ccccc|}
\hline \multirow{2}{*}{ Subscale } & \multicolumn{2}{l}{ Item Trait Interaction } & PSI & Unidimensionality* \\
& Value $(d f)$ & $p$ & & 1.667 \\
\hline Motivation to Teach & $15.1(8)$ & .06 & .67 &
\end{tabular}




\begin{tabular}{|c|c|c|c|c|}
\hline Teacher Efficacy & $10.1(14)$ & .76 & .83 & 1.596 \\
\hline Willingness to Learn & $10.0(6)$ & .13 & .64 & 1.551 \\
\hline Conscientiousness & $08.0(6)$ & .23 & .74 & 1.722 \\
\hline $\begin{array}{l}\text { Interpersonal \& } \\
\text { Communication } \\
\text { Skills }\end{array}$ & $10.9(14)$ & .70 & .82 & 1.588 \\
\hline
\end{tabular}

Note. $p \mathrm{~s}<0.05$ are significant $*$ Eigenvalues of the first dominant factor loading of the PCA on the standardised residuals (eigenvalues $<2.0$ are considered to indicate random noise, i.e., unidimensionality, Linacre, 2011).

\section{Model Fit}

In order to determine if the five scales function as linear measures a chi-square $\left(X^{2}\right)$ test (item-trait interaction) was conducted. Specifically, the $X^{2}$ statistic provides a measure of overall fit of the data to the Rasch model, the null hypothesis being that the data fits the Rasch model. Therefore, a statistically significant result (i.e., $p<0.05$ ) indicates that the data does not fit the model and that there is a problem with the functioning of the scale. Also important is the Person Separation Index (PSI), a reliability index comparable to a Cronbach's alpha, where a coefficient of 0.70 and above is considered reliable.

Overall, good model fit was found for the scales Teacher Efficacy, $X^{2}(14)=10.1$, $n s$, Conscientiousness, $X^{2}(6)=8.0, n s$, and Interpersonal and Communication Skills, $X^{2}(14)=10.9, n s$. Poor fit to the Rasch model was found in two scales - Motivation to Teach and Willingness to Learn, each with significant item-trait interactions $(p s<$ 0.03). However, good fit of the data to the Rasch model was achieved with the removal of item 22 in Motivation to Teach and item 18 in Willingness to Learn (all $p s n s$ ). These results indicated that the data from all five subscales were not significantly different from Rasch-derived expectations. The PSI indicated marginal to good reliability for all scales $(.64-.83)$. These results suggest that the five subscales were valid and reliable. 


\section{Item Fit}

In addition to testing the collective functioning of the items through model fit and reliability analyses, it is also important to test the functioning of individual items. There are a number of ways in a Rasch analysis to test if the items function as intended (i.e., as a linear measure). A misfitting (poor functioning) item can be detected when fit residuals exceed the acceptable range (less than -2.50 or greater than 2.50 ). Fit residuals are the difference between the data and Rasch estimates. Hence, a fit residual should be small. The significance of the distance between data and Rasch estimates is evaluated with chi-square tests and analyses of variances, where the null hypothesis is that the item fits the model well. Hence, a statistically significant $p$ value $(p<0.05)$ indicates a misfitting item. Item misfit was found in the scale Motivation to Teach (item 22) and in Willingness to Learn (item 18) (see Table 4). The Appendix provides the final version of the survey with these two items removed.

Table 4. Individual item fit for the five scales.

\begin{tabular}{|cccccc|}
\hline \multicolumn{6}{|l}{ Motivation to Teach } \\
\hline Item Number & Fit Residual & ChiSq & $P$ & $F$ & $P$ \\
15 & 0.736 & 2.243 & 0.326 & 0.601 & 0.549 \\
20 & -0.813 & 3.380 & 0.184 & 1.792 & 0.169 \\
21 & -1.395 & 2.028 & 0.363 & 1.522 & 0.221 \\
23 & -0.341 & 1.280 & 0.527 & 0.084 & 0.919 \\
\hline Teacher Efficacy & & & & & \\
\hline 1 & -1.098 & 1.951 & 0.377 & 1.314 & 0.272 \\
2 & 0.093 & 0.800 & 0.670 & 0.304 & 0.738 \\
3 & -0.280 & 1.118 & 0.572 & 0.320 & 0.726 \\
6 & -0.694 & 0.236 & 0.889 & 0.138 & 0.871 \\
8 & -0.099 & 2.567 & 0.277 & 0.962 & 0.384 \\
9 & -0.798 & 0.795 & 0.672 & 0.235 & 0.791 \\
12 & 0.290 & 2.596 & 0.273 & 0.831 & 0.437 \\
\hline Willingness to Learn & & & & \\
\hline 16 & -0.607 & 2.585 & 0.274 & 2.031 & 0.134 \\
17 & -0.444 & 4.588 & 0.101 & 2.502 & 0.085
\end{tabular}




\begin{tabular}{|cccccc|}
\hline 19 & 0.253 & 2.769 & 0.251 & 1.214 & 0.299 \\
\hline \multicolumn{7}{|c}{ Conscientiousness } & & & & \\
\hline 24 & -0.883 & 4.247 & 0.119 & 3.053 & 0.050 \\
25 & -0.300 & 1.124 & 0.570 & 0.022 & 0.978 \\
26 & 0.153 & 2.651 & 0.266 & 1.885 & 0.155 \\
\hline \multicolumn{7}{|c}{ Interpersonal \& } & Communication Skill & & & \\
\hline 4 & -0.444 & 0.122 & 0.940 & 0.003 & 0.997 \\
5 & 0.057 & 1.645 & 0.439 & 0.982 & 0.377 \\
7 & -0.824 & 2.510 & 0.285 & 1.997 & 0.139 \\
10 & 0.187 & 0.064 & 0.969 & 0.007 & 0.993 \\
11 & 1.080 & 4.834 & 0.089 & 2.569 & 0.080 \\
13 & 0.327 & 0.577 & 0.749 & 0.320 & 0.727 \\
14 & -0.093 & 1.114 & 0.573 & 0.640 & 0.528 \\
\hline Misfitting Items & & & & & \\
\hline 22 & $\mathbf{- 4 . 0 6 4}$ & 11.443 & $\mathbf{0 . 0 0 3}$ & 15.521 & $\mathbf{0 . 0 0 1}$ \\
18 & -1.073 & 8.939 & $\mathbf{0 . 0 1 1}$ & 6.041 & $\mathbf{0 . 0 0 3}$ \\
\hline
\end{tabular}

Note. Items with fit residuals $<-2.5$ and $>2.5$ are considered misfitting. Bonferroni adjusted $p$ values are significant at $p<.0025 ; .05 / 4$ (Motivation to Teach); $p<.007 ; .05 / 7$ (Teacher Efficacy); $p<.016 ; .05 / 3$ (Willingness to Learn); $p<.016 ; .05 / 3$ (Conscientiousness); $p<$ $.007 .05 / 7$ (Interpersonal and Communication Skill).

\section{Unidimensionality}

Scales, or subscales, should measure a single latent trait only (i.e., be unidimensional) if accurate measurement is to be achieved (Wright, 1997). In a Rasch analysis, a scale's unidimensionality is affirmed by a non-significant item-trait interaction and further post hoc tests such as a principal components analysis (PCA) on the standardised residuals (cf., Hagell, 2014). In a PCA analysis the idea is that, if a scale is unidimensional, then no discernible patterns should be detected in the standardised residuals. The detection of a pattern in the standardised residuals indicates the capture of additional dimensions (or constructs) by the (sub)scale beyond the core construct it is capturing. Patterns in the standardised residuals are identified by first PC loadings with large eigenvalues (> 2.0; Linacre, 2011). In our analysis, PCA of the standardised residuals provided evidence of unidimensionality on all five subscales (all eigenvalues on the first PC loading were $<$ 
2.0; Table 2).

\section{Discussion}

This study outlined the process of development and validation of a scale to measure key dispositional factors that are conducive to successful teaching and learning among NSW primary school teachers. Research has yet to establish a core set of teacher dispositions, behaviours associated with these dispositions, and a suitable tool (i.e., valid, reliable, sensitive to change) with which to assess the current state of pre- and in-service teachers' dispositions. Without these insights, it becomes difficult to identify and foster effective teacher dispositions more broadly, or at an individual level, to promote professional behaviours that are associated with improved personal, student, school, and systemic outcomes. Creation and validation of the TDS has indicated five core teacher dispositions, subsuming many previously proposed dispositions, each with unique associated behaviours. Validation of the scale using modern test theory (Rasch analysis) approaches provided preliminary evidence that the TDS functions well, according to the principles of linear measurement, and was valid and reliable.

While various characteristics and dispositions of effective teachers have been suggested in the literature, the extent to which these characteristics and dispositions overlap and which are particularly crucial is unclear. In compiling this literature, and consulting with HATs, we derived a list of disposition-related behaviours that they deemed essential to effective teaching. Notably, this list did not include all factors identified in the literature (these were deemed less essential by the HATs) and included some that were not. Subsequent consideration of government policy and empirical evaluation of these behaviours derived a core set of five dispositions essential for effective teaching: Motivation to Teach, Teacher Efficacy, Willingness to Learn, 
Conscientiousness, and Interpersonal and Communication Skills.

It is uncommon for a disposition instrument to be developed from such a complex set of procedures, involving an extensive literature review, community consultation, and empirical validation (O’Neill, Hansen, and Lewis, 2014). Most instruments rely upon literature, filtered through consultation limited primarily to researchers. This process can often produce repetitious or superfluous items, which may distort dispositional assessment (Lang and Wilkerson, 2008). The TDS contained such items within the common themes of existing instruments, including enthusiasm, professional growth, reflexivity and relationships (Young and Wilkins, 2008). However, the original TDS was streamlined through empirical validation to produce a set of core items and subscales, where some subscales were subsumed into core dispositions. Few existing instruments move beyond face validity (Lang and Wilkerson, 2008), and these often face criticism for focusing on either a character-based or competence-based interpretation of dispositions, with the former ill-suited to quantification (Schussler, 2006). By combining developmental elements of both character- and competence-based instruments, the TDS seeks to provide a potentially meaningful instrument that takes stakeholder consultation beyond face validity.

In empirically deriving a core set of dispositions, our analysis additionally suggested behaviours associated with each of these dispositions. These dispositions share similarities with those identified by Young and Wilkins (2008) as common dispositions associated with effective teaching, in their review of 32 existing Initial Teacher Education (ITE) disposition instruments. Young and Wilkins' 13 dispositions are also associated with defined observable behaviours, providing a point of comparison for the TDS. These included accepting criticism, ethics, professional growth, 
relationships, service to school and work habits. Other common dispositions are grouped as thinking habits (critical thinking, reflectivity, respect for learning) or personality characteristics (enthusiasm, leadership, personality, self-confidence) that may also be exhibited as behaviour (ibid). When compared to the behaviours within the TDS, almost all corresponded with those of the common dispositions; however, they are distributed differently across the five TDS dispositions. Motivation to Teach is used in place of the common disposition, Enthusiasm. The two concepts are theoretically related (Eccles and Wigfield, 2002) and expand upon the widely assessed disposition of Fairness (NCATE, 2008) through the TDS factor, Teacher Efficacy.

Where the TDS deviates from common dispositions found in existing instruments is the consideration of professionalism outside of the school context. This behaviour is part of the Conscientiousness disposition and is distinct from the Teacher Efficacy behaviour relating to professionalism inside the school context. While professionalism inside the school context can be considered a 'work habit' behaviour, professionalism exhibited outside employment contexts implies the pervasiveness of a disposition toward professionalism

\section{Implications for Research and Practice}

The TDS represents a starting point from which future research can better understand dispositions, their associated constructs and the contexts in which they exist. This instrument has implications for selection criteria in ITE, pre- and in-service assessment, and investigations making links between teacher dispositions and student outcomes. While existing measures of teacher dispositions exist, often these have been derived without either consultation with those most experienced in the field (Garner, Freeman, and Lee, 2016; Wasicsko, Wirtz, and Resor, 2009), or subjection to rigorous evaluation 
(Almerico, Johnston, Henriott, and Shapiro, 2011; O’Neill, Hansen, and Lewis, 2014).

The creation of the TDS thus supports important future research seeking to understand the development and importance of dispositions over the course of teachers' careers. In particular, investigating the relationship between specific teacher dispositions and student outcomes is an area requiring researchers' focus. This research could have implications not only for education, but also for the broader psychological study of dispositions and related constructs, such as motivation, values and attitudes.

The TDS also has potential applications to teacher development. As with existing scales, it may be used to assess potential teaching candidates as part of entry criteria into ITE programmes, thus possibly curtailing attrition among novice teachers by assessing early suitability. Such usage has become commonplace (O’Neill, Hansen, and Lewis, 2014), but presents both practical and ethical issues. Relying on the assessment of candidates' dispositions alone is an inadequate indicator of their aptitude for teaching, so disposition scales form part of a suite of assessments that may include interviews, academic transcripts and character references. Further research examining TDS' sensitivity of the TDS to change over the course of pre-service training and prediction of real-world outcomes (e.g., job attainment, performance reviews, accolades, student evaluations and performance) is needed to establish the appropriateness of such use.

The TDS also addresses international objections regarding the ethical use of disposition scales as a screening tool, with some fearing that the unclear distinction between 'beliefs', 'values' and 'dispositions' could lead to the unfair exclusion of social or cultural groups from ITE (Sinclair, 2008). Some have also questioned the inherent logic of denying a candidate entry into ITE programmes based on the absence of 
dispositions not yet given the opportunity to develop (Rockoff, Jacob, Kane, and Staiger, 2011). These objections stem from whether dispositions are viewed as fixed traits or learned behaviours. The TDS is built upon desirable, observable and malleable behaviours, providing the scope for change to occur and be detected. Such change would be of interest to ITE programme coordinators, applicants to education programmes (as a self-assessment of 'fit' with the teaching profession), pre-service teachers (to self-assess change over time), and professional placement supervisors (to provide external feedback for continued development, related not only to contextual behaviours, but also more pervasive patterns of behaviour).

\section{Limitations of the Study}

The TDS was piloted on pre-service primary teachers in a single core-subject lecture. While our psychometric evaluation of the scale involved Rasch analysis, which is considered to be sample independent (see Wright, 1997), it is important that the instrument continues to be evaluated in relation to its discriminatory ability across a variety of samples, contexts and uses. For example, further research is required to comment on the scale's transferability to other contexts, such as for secondary teachers whose work, and therefore desired dispositions, may be distinct from those of a primary teacher sample. Similarly, the scale also needs to be considered for inter-state and international teachers. Although there is some early research suggesting dispositions may be largely universal (Shao and Tamashiro, 2013), the items of the TDS may also cluster differently than in the current sample. The self-reported instrument provided low-cost, easily-distributed data collection, though acknowledging a potential for bias or manipulation. As such, this limitation would be minimised by future work identifying possible correlations between intended behaviour (disposition) and actual behaviour. 
In the TDS disposition, Willingness to Learn, behaviours related to promoting students' self-directed learning and holding high expectations of students sit alongside those about teachers' own professional learning. While the grouping of these behaviours may appear broad, teachers' own ways of thinking about learning have been shown to impact their students' learning. For instance, teachers' attitudes toward and aptitudes for STEM subjects have been linked to students' own perceptions and performance (Ertmer, Ottenbreit-Leftwich, Sadik, Sendurur, and Sendurer, 2012; Rice, Lopez, and Richardson, 2013). The TDS reflects this reality in Willingness to Learn, which captures this responsibility of influence as an aspect of teachers' professionalism. Further empirical evaluation of dispositions can be seen as a strength, as seen in cases where our results suggest that dispositions previously proposed as discrete actually seem to be subserved by a common, underlying disposition.

\section{Conclusion}

The creation of a well-functioning TDS establishes a fruitful line for future investigations. Extending beyond validity and reliability evidence often available in measures of professional dispositions, all sub-scales also demonstrated good psychometric properties according to the specifications of the Rasch model; that is, they fit the model well, had marginal to good reliability coefficients, and indicated evidence that they were measuring a single latent trait (i.e. a unidimensional construct). This sound empirical validation gives the TDS a strong advantage over existing disposition scales. The strength of the scale was further increased through the inclusion of community and literature consultation. The scale is timely in light of Australia's recent educational reforms, but also contributes to an international need for communityconsultative, validated tools that support better opportunities, outcomes and experiences 
for educators and the children and families they support. While the TDS is in its early stages of development, it shows promise for making global contributions to the field of teacher education. 


\section{References}

AITSL [Australian Institute for Teaching and School Leadership]. (2015). Action Now: Selection of Entrants into Initial Teacher Education, Guidelines. Melbourne, Australia: AITSL [Australian Institute for Teaching and School Leadership]. https://www.aitsl.edu.au/tools-resources/resource/action-now-selection-of-entrantsinto-initial-teacher-education - guidelines.

Almerico, G., Johnson, P., Henriott, D., \& Shapiro, M. (2011). Dispositions assessment in teacher education: Developing an assessment instrument for the college classroom and the field. Research in Higher Education Journal, 11, 1-19.

Andrich, D., Sheridan, B., \& Luo, G. (2010). RUMM2030: A Windows Program for the Rasch Unidimensional Measurement Model. Perth, Australia: RUMM Laboratory. 510

Barber, M., \& Mourshed, M. (2007). How the World's Best Performing School Systems Come Out on Top. New York, NY: McKinsey and Company.

Borko, H., Liston, D., \& Whitcomb, J. A. (2007). Apples and Fishes: The debate over dispositions in teacher education. Journal of Teacher Education, 58(5), 359-364. doi:10.1177/0022487107309977.

CESE (Centre for Education Statistics and Evaluation). (2013). Great Teaching, Inspired Learning: What Does the Evidence 515 Tell Us about Effective Teaching? Sydney, Australia: CESE.

Cornelius-White, J. (2007). Learner-Centred Teacher-Student Relationships are Effective: A Meta-Analysis. Review of Educational Research, 77(1), 113-143. doi:10.3102/003465430298563. 
Damon, W. (2007). Dispositions and Teacher Assessment: The need for a more rigorous definition. Journal of Teacher Education, 58(5), 365-369. doi:10.1177/0022487107308732.

Darling-Hammond, L. (2006). Constructing 21st-Century Teacher Education. Journal of Teacher Education, 57(3), 300- 314. doi:10.1177/0022487105285962.

Diez, M. E. (2007). Looking Back and Moving Forward: Three tensions in the teacher dispositions discourse. Journal of Teacher Education, 58(5), 388-396. doi:10.1177/0022487107308418.

Eccles, J. S., \& Wigfield, A. (2002). Motivational beliefs, values and goals. Annual Review of Psychology, 53(1), 109- 525. doi:10.1146/annurev.psych.53.100901.135153.

Ertmer, P. A., Ottenbreit-Leftwich A. T., Sadik, O., Sendurur, E., \& Sendurur, P. (2012). Teacher beliefs and technology integration practices: A critical relationship. Computers and Education, 59(2), 423-435. doi:10.1016/j. compedu.2012.02.001.

Fernet, C., Guay, F., Senécal, C., \& Austin, S. (2012). Predicting intra-individual changes in teacher burnout: The role 530 of perceived school environment and motivational factors. Teaching and Teacher Education, 28(4), 514-525. doi:10.1016/j.tate.2011.11.013.

Field, A. (2009). Discovering Statistics Using IBM SPSS Statistics. London: SAGE Publications.

Fishbein, M., \& Ajzen, I. (2010). Predicting and Changing Behavior: The Reasoned Action Approach. New York, NY: Psychology Press.

Garner, C., Freeman, M. B. J., \& Lee, L. (2016). Assessment of student dispositions: The development and psychometric properties of the professional disposition 
competence assessment (PDCA). Ideas and Research You Can Use: VISTAS 52: 114.

Hagell, P. (2014). Testing rating scale unidimensionality using the principal component analysis (Pca)/T-test protocol with the Rasch Model: The primacy of theory over statistics. Open Journal of Statistics, 4, 456-465. doi:10.4236/ 540ojs.2014.46044.

Kyriacou, C., \& Kunc, R. (2007). Beginning teachers' expectations of teaching.

Teaching and Teacher Education, 23(8), 1246-1257. doi:10.1016/j.tate.2006.06.002.

Lang, S. W., \& Wilkerson, J. R. (2008). Measuring teacher disposition with different item structures: An application of the Rasch Model to a complex accreditation requirement. Online submission to the Annual Meeting of the American Educational Research Association. New York: American Educational Research Association.

Linacre, J. (2011). WINSTEPS Rasch Measurement Computer Program [Computer Software]. Chicago, IL: Winsteps.

Masters, G. N. (1982). A Rasch Model for partial credit scoring. Psychometrika, 47, 149-174. doi:10.1007/BF02296272.

McConney, A., Price, A., \& Woods-McConney, A. (2012).. Fast Track Teacher Education: A Review of the Research Literature on 'Teach for All' Schemes. Perth, WA: Murdoch University Centre for Learning, Change and Development.

NCATE [National Council for Accreditation of Teacher Education]. (2008).

Professional Standards for the Accreditation of Schools, Colleges, and Departments of Education. Washington, DC: NCATE.

NSW DEC [New South Wales Department of Education and Communities]. (2013). Initial Teacher Education: A Blueprint for Action. Sydney, Australia: NSW DEC. NSW DEC [New South Wales Department of Education and Communities]. (2015). 2015 Teaching Workforce Supply andDemand. Sydney, Australia: NSW DEC. 
NSW DEC [New South Wales Department of Education and Training]. (2009). Smarter Schools National Partnership on Improving Teacher Quality: Highly Accomplished Teachers in NSW Government Schools Guidelines. Sydney: NSW DET.

O’Neill, J., Hansen, S., \& Lewis, E. (2014). Dispositions to Teach: Review and Synthesis of Current Components and Applications, and Evidence of Impact. Wellington. New Zealand: Massey University, Institute of Education.

OECD [Organisation for Economic Co-operation and Development]. (2005). Teachers Matter: Attracting, Developing and Retaining Effective Teachers. Paris, France: OECD Publishing.

Paris, L. (2010). Reciprocal Mentoring Residencies: Better Transitions to Teaching. Australian Journal of Teacher Education, 35(3), 14-26. doi:10.14221/ajte.2010v35n3.2.

Rice, K. G., Lopez, F. G., \& Richardson, C. M. E. (2013). Perfectionism and performance among STEM students. Journal of Vocational Behavior, 82(2), 124134. doi:10.1016/j.jvb.2012.12.002.

Rice, S., Volkoff, V., \& Dulfer, N. (2015). 'Teach For'/'Teach First' Candidates: What conclusions do they draw from their time in teaching? Teachers and Teaching: Theory and Practice, 21(5), 497-513. doi:10.1080/13540602.2014.995474.

Rockoff, J., Jacob, B., Kane, T., \& Staiger, D. (2011). Can you recognize an effective teacher when you recruit one? Education Finance and Policy, 6(1), 43-74. doi:10.1162/EDFP_a_00022.

Schussler, D. L. (2006). Defining dispositions: Wading through murky waters. The Teacher Educator, 41(4), 251-267. doi:10.1080/08878730609555387. 
Schussler, D. L., Bercaw, L. A., \& Stooksberry, L. M. (2008). The fabric of teacher candidate dispositions: What case studies reveal about teacher thinking. Action in Teacher Education, 29(4), 39-52. doi:10.1080/ 575 01626620.2008.10463468.

Shao, K., \& Tamashiro, R. (2013). Comparing teacher dispositions in China and the USA." Research in Higher Education, 21, 1-7.

Sinclair, C. (2008). Initial and changing student teacher motivation and commitment to teaching. Asia Pacific Journal of Teacher Education, 36(2), 79-104. doi:10.1080/13598660801971658. 580

Stronge, J. H., Ward, T. J., \& Grant, L. W. (2011). What makes good teachers good? A cross-case analysis of the connection between teacher effectiveness and student achievement. Journal of Teacher Education, 62(4), 339- 355. doi:10.1177/0022487111404241

TEMAG [Teacher Education Ministerial Advisory Group]. (2014). Action Now: Classroom Ready Teachers. Canberra, Australia: Australian Government Department of Education and Training.

Tennant, A., \& Conaghan, P. G. (2007). The Rasch Measurement Model in Rheumatology: What is it and why use it? When should it be applied, and what should one look for in a Rasch paper? Arthritis Care \& Research, 57(8), 1358-1362. doi:10.1002/art.23108.

Wasicsko, M., Wirtz, P., \& Resor, C. (2009). Using dispositions in the teacher admission process. Journal of the Southeastern Regional Association of Teacher Educators, 18(2), 19-26.

Welch, F. C., Pitts, R. E., Tenini, K. J., Kuenlen, M. G., \& Wood, S. G. (2010). Significant issues in defining and assessing teacher dispositions. The Teacher Educator, 45(3), 179-201. doi:10.1080/08878730.2010.489992. 
White, P., Gorard, S., \& See, B. H. (2006). What are the problems with teacher supply? Teaching and Teacher Education, 22(3), 315-326. doi:10.1016/j.tate.2005.11.002.

Wright, B. D. (1997). A history of social science measurement. Educational Measurement: Issues and Practice, 16(4), 33- 595 45. doi:10.1111/j.17453992.1997.tb00606.x.

Young, A., \& Wilkins, E. (2008). Dispositional statements on student teacher evaluation instruments: Commonalities across institutions. The Teacher Educator, 43(3), 198215. doi:10.1080/08878730802055115. 
Appendix A. Final Teacher Disposition Scale, arranged by subscale.

For each statement, please CIRCLE the number that best describes the frequency with which you would undertake that behaviour in your teaching.

\begin{tabular}{|c|c|c|c|c|c|c|c|}
\hline & \multicolumn{4}{|c|}{ Never } & \multicolumn{3}{|c|}{ All the Time } \\
\hline \multicolumn{8}{|l|}{ Subscale 1: Motivation to Teach } \\
\hline 15. Treats everyone fairly and equitably & 0 & 1 & 2 & 3 & 4 & 5 & 6 \\
\hline 20. Shows a passion for teaching & 0 & 1 & 2 & 3 & 4 & 5 & 6 \\
\hline $\begin{array}{l}\text { 21. Demonstrates a passion and responsibility for } \\
\text { students' learning }\end{array}$ & 0 & 1 & 2 & 3 & 4 & 5 & 6 \\
\hline $\begin{array}{l}\text { 22. Understands their role and responsibilities in the } \\
\text { school context }\end{array}$ & 0 & 1 & 2 & 3 & 4 & 5 & 6 \\
\hline 23. Demonstrates a commitment to students' learning & 0 & 1 & 2 & 3 & 4 & 5 & 6 \\
\hline \multicolumn{8}{|l|}{ Subscale 2: Teacher Efficacy } \\
\hline $\begin{array}{l}\text { 1. Considers and employs a variety of effective teaching } \\
\text { strategies }\end{array}$ & 0 & 1 & 2 & 3 & 4 & 5 & 6 \\
\hline $\begin{array}{l}\text { 2. Approaches the teaching profession with adequate } \\
\text { preparation }\end{array}$ & 0 & 1 & 2 & 3 & 4 & 5 & 6 \\
\hline $\begin{array}{l}\text { 3. Demonstrates strong overall teacher professionalism at } \\
\text { all times inside the school context }\end{array}$ & 0 & 1 & 2 & 3 & 4 & 5 & 6 \\
\hline $\begin{array}{l}\text { 6. Engages all students to participate inclusively in } \\
\text { communications and collaborations }\end{array}$ & 0 & 1 & 2 & 3 & 4 & 5 & 6 \\
\hline $\begin{array}{l}\text { 8. Displays genuine empathy, warmth and compassion for } \\
\text { students }\end{array}$ & 0 & 1 & 2 & 3 & 4 & 5 & 6 \\
\hline 9. Engages in effective classroom management strategies & 0 & 1 & 2 & 3 & 4 & 5 & 6 \\
\hline 12. Appreciates students' individual differences & 0 & 1 & 2 & 3 & 4 & 5 & 6 \\
\hline \multicolumn{8}{|l|}{ Subscale 3: Willingness to Learn } \\
\hline 16. Fosters students' self-directed learning & 0 & 1 & 2 & 3 & 4 & 5 & 6 \\
\hline 17. Seeks support and advice from others & 0 & 1 & 2 & 3 & 4 & 5 & 6 \\
\hline $\begin{array}{l}\text { 18. Incorporates professional learning and feedback into } \\
\text { practice }\end{array}$ & 0 & 1 & 2 & 3 & 4 & 5 & 6 \\
\hline 19. Has high expectations of students & 0 & 1 & 2 & 3 & 4 & 5 & 6 \\
\hline
\end{tabular}




\begin{tabular}{|c|c|c|c|c|c|c|c|}
\hline & \multicolumn{4}{|c|}{ Never } & \multicolumn{3}{|c|}{ All the Time } \\
\hline \multicolumn{8}{|l|}{ Subscale 4: Conscientiousness } \\
\hline 24. Shows a commitment to teaching & 0 & 1 & 2 & 3 & 4 & 5 & 6 \\
\hline $\begin{array}{l}\text { 25. Demonstrates strong overall teacher professionalism } \\
\text { at all times outside the school context }\end{array}$ & 0 & 1 & 2 & 3 & 4 & 5 & 6 \\
\hline 26. Foresees the need to differentiate for diverse students & 0 & 1 & 2 & 3 & 4 & 5 & 6 \\
\hline \multicolumn{8}{|l|}{ Subscale 5: Interpersonal \& Communication Skills } \\
\hline $\begin{array}{l}\text { 4. Demonstrates on-going effective collaboration with } \\
\text { whole school community }\end{array}$ & 0 & 1 & 2 & 3 & 4 & 5 & 6 \\
\hline 5. Engages in effective problem solving strategies & 0 & 1 & 2 & 3 & 4 & 5 & 6 \\
\hline $\begin{array}{l}\text { 7. Possesses strong verbal communication skills } \\
\text { (speaking and listening) }\end{array}$ & 0 & 1 & 2 & 3 & 4 & 5 & 6 \\
\hline 10. Engages in reflective practices of pedagogy & 0 & 1 & 2 & 3 & 4 & 5 & 6 \\
\hline $\begin{array}{l}\text { 11. Shows a willingness to facilitate extra-curricular } \\
\text { activities }\end{array}$ & 0 & 1 & 2 & 3 & 4 & 5 & 6 \\
\hline 13. Possesses strong written communication skills & 0 & 1 & 2 & 3 & 4 & 5 & 6 \\
\hline 14. Possesses strong non-verbal communication skills & 0 & 1 & 2 & 3 & 4 & 5 & 6 \\
\hline
\end{tabular}

